original possessors of the soil. In fact, they had all the qualities of a domineering, not to say dominant, race, and the features of their. kings and. lords, as handed down to us by their stony effigies, show many of the characters of the mesocephalic long-head. This, then, was the race who first evolved from the recesses of their brains how to lead an easy life by militarism and "kultur."

\section{THE' EARLY TREATMENT OF PROJECTILE WOUNDS BY EXCISION OF THE DAMAGED TISSUES.}

By E. T. C. MILLIGAN, M.D., B.S.Melb., Lieutenant, R.A.M.C., British Expeditionaty Force.

AFTER eight montlis of experience of the early treatment of projectile wounds l have had ample opportunity of critically observing the values of the various antiseptics in their various strengths and also the many details of treatment of recent wounds. I desire, therefore, to place on record a method of treatment which has given most gratifying results, and which, if practised thoroughly, will materially lessen the time a wounded man is absent from the firing line.

In a modern projectile wound we have to deal with a varying amount of devitalized tissue and a varying amount of ingrained infected material, both of which are always present. - The devitalized tissue varies in different wounds from a microscopical amount, through all quantities, to the gross obvious slough. The ingrained infected material is inseparably fixed to this devicalized tissue, and nothing short of the complete removal of the tissue can possibly get rid of the infected matter. Cleansing measures are placed at a great disadvantage, for only those organisms which are spread loosely broadcast on the surfaces can be removed or inhibited in growth by antiseptics. The more important natural protective powers of the healthy body in which these wounds occur are also placed at a great disadvantage, for no vigorous opposition can be offered by devitalized tissue, and the healthy tissue is separated fron the loosely scattered infected material on the surface of the wound by the layer of devitalized tissue bounding the wound, and this tissue also acts as a perfect culture medium.

The Method.

This consists in the extirpation of the devitalized tissues. An anaesthetic is given where indicated:

Local anaesthesia by novocain and adrenalin $2 \frac{1}{2}$ per cent.

Short anaesthesia by open ethyl cliloride method.

Long anaesthesia by ether or chloroform.

The wound of the skin is boldly cut ont with a sharp scalpel. It should be so completely removed that a clean healthy incised wound replaces the contused and infected wound made by the projectile. There should be nothing of the old wound remaining.

The wound of the superficial and deep fascia should be treated in the same way.

The wound of the muscle is dealt with in the same fashion. It presents, however, more difficulties because of the retraction of severed fibres, and because of the distance of the depths of the wound from the surface of the body. This latter difficulty can be happily overcome in many cases by making larger incisions.

Removal of loose and fixed bits of obvious foreign and clead matter is, of course, essential. Ample exposure and drainage of the wound is necessary, and those wounds which are too extensive after the above treatment to retain a drainage tube do better than those in which a tube is necessary on account of their depth and narrowness. By this procedure the wound is put in the best possible conditions for the bactericidal actions of the tissues and the outpoured lymph. It is important to remark that it is not wise to impair the resisting and offensive powers of the artificially obtained healthy tissue surfaces by the use of strong or injurious antiseptics.

\section{Results.}

This method, when combined with the surgical essentials of perfect rest, cleanliness, and frequent suitable dressings, has resulted in the healing of projectile wounds, withont any appearance of pus in wounds of the skin and of tho superficial fascia. In many wounds of muscle and bone, also, this gratifying result has been attained. In the treatment of some wounds of bone and muscle anatomical problems have prevented these principles of treatment from being thoroughly carried out, so that the results have not been as good. There have been no cases of generalized blood infection, nor of any spreading infection in the neighbourhood of the wound

\section{NON-TUBERCULOUS HIP DISEASE SLCCESS FULLY TREATED BY DOUBLE SPLINT AND OVER-ABDUCTION.}

By RUSHTON PARKER, M.B., B.S., F.R.C.S., PROFESSOR OF SURGERY IN THE CNIVERSTTY OF' LIVERPOOL.

THE case which was subjected to the treatment below described was sent to Liverpool by Dr. Sugden of Ramsey, Isle of Man. The illustrations are admirably drawn from photographs.

A girl, aged 6, was admitted into the Liverpool Royal Infirmary on June 8th, 1903. The left.hip was disabled. swollen, and tender, but gave no pain as long as she lay quiet in bed. The condition started with pain nime months previously, and she had been lame for six months. The pelvis was strongly arched and tilted to the left, and the limb abducted and rotated outwards. There was a conspicuous feature on manipulation-an extraordinary looseness of the hip-joint manipulation-an extraordinary looseness of the hip-joint whereby the left thigh could be adducted so as to lie at right
angles across the right. She was measured for a double angles across the right. She was measured for a double Thomas's hip-splint as modified by Robert Jones, with extra abduction on the affected side and the ends prolonged, as show

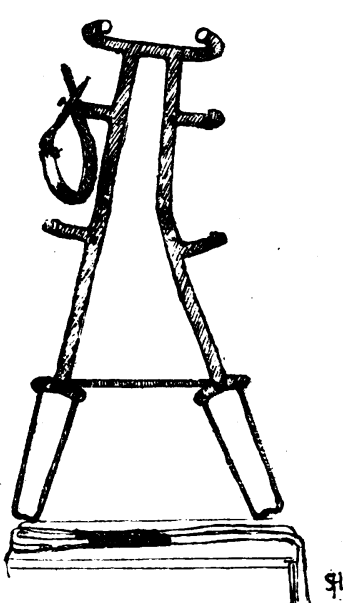

Fig. 1.

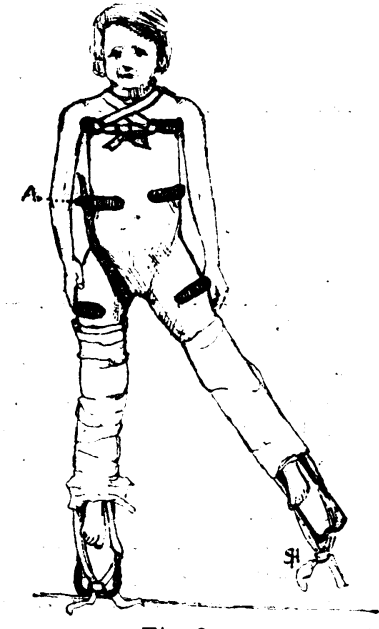

Fig. 2
Fig. 1.-Double hip splint, with extra abduction on left sire. Leather perineal band for sound side attached to stud on loin

Fig. 2. - Cbild erect in splint. Front view, showing banduge sliuging it to neck. $A$, Stud to which strap is fixed.

1903; both lower limbs being thickly surrounded with rolls of cotton wadding and bandaged to the splint. To prevent shifting, each les was previously prepared with two strips of bandage stuck on with doubled adhesive plaster fixed under a roller bandage, and tied to the ends of the splint beyond the feet. For counter-extension a perineal band covered with basil leather was looped on the sound side, aud its ends-leather straps pierced with holes-were buttoned on couple of metal studs attached to the splint, as shown in Fiss. 1 and 2. Between the patient's back and the bair of the splint was a flat pad covered with basil leather.

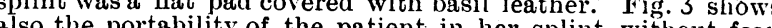
f of displace mechanical treatment. She could, whenever tired of lying on her back, be turned over so as to lie on her face. The invariable tendency to "arlduction deformity" on recovery from severe hip disease is thus counteracted by "over abduction" at first, the result being eventual return to the straight position. Some pain was naturally inflicted by the forced adoption of this attitude, but quickly subsided under the fixed rigidity the splint. Still the evening temperature, thoush sometimes returning to normal, generally oscillated in the first few rver between $100^{\circ}$ and $102^{\circ} \mathrm{F}$. The first few wefks and after seven weeks fluid elasticity could be felt. Oil 